\title{
The impact of risk factors on gastroparesis at an urban medical center
}

\author{
Katherine Duffeya*, Michelle Hannon ${ }^{a *}$, Joseph Yoob ${ }^{b}$ Nicholas Perkonsc, Charles Intenzod, \\ Stephanie Moleski ${ }^{b}$, Anthony J. DiMarino ${ }^{b}$
}

Thomas Jefferson University Hospital; University of Pennsylvania, Philadelphia, USA

\section{Abstract}

aDepartment of Medicine, Division of Internal Medicine, Thomas Jefferson University Hospital, Philadelphia, PA (Katherine Duffey, Michelle Hannon); ${ }^{b}$ Department of Medicine, Division of Gastroenterology and Hepatology, Thomas Jefferson University, Philadelphia, PA (Joseph Yoo, Stephanie Moleski, Anthony J. DiMarino); 'Perelman School of Medicine, University of Pennsylvania, Philadelphia, PA (Nicholas Perkons); 'Department of Radiology, Division of Nuclear Medicine and Molecular Imaging, Thomas Jefferson University, Philadelphia, PA (Charles Intenzo), USA

*These authors contributed equally

\section{Conflict of Interest: None}

Correspondence to: Anthony J. DiMarino, MD, 132 South 10th Street, Suite 480, Philadelphia PA 19107, USA, e-mail: Anthony.DiMarino@ jefferson.edu

Received 28 August 2019; accepted 29 January 2020; published online 2 April 2020

DOI: https://doi.org/10.20524/aog.2020.0475

\section{Introduction}

Gastroparesis is a syndrome of objective delayed gastric emptying (DGE) in the setting of symptoms such as nausea, vomiting, early satiety, bloating, and upper abdominal pain, and in the absence of a mechanical obstruction [1,2]. The gold standard for diagnosis is gastric emptying scintigraphy (GES) [2,3]. The epidemiology of gastroparesis in the community is not well described. Two previous studies have described the epidemiology of the disease, but these were limited to relatively uniform suburban and rural locations $[4,5]$.

While a multitude of etiologies of gastroparesis have been suggested, most studies group patients into 2 categories: diabetic and idiopathic. Diabetic gastroparesis has been extensively studied [6-11], but the most common form of gastroparesis is thought to be idiopathic, with a possible correlation to a prior viral infection $[2,12,13]$. Other cases of gastroparesis can be attributed to various medications, post- 
surgical changes, neurologic diseases, autoimmune syndromes, and connective tissue disease [14-21].

The relationship between patient demographics, the objective severity of DGE, and the specific etiology of the disease is not well understood. Our goal was to describe the most common comorbidities among an urban patient population diagnosed with gastroparesis and to determine whether certain comorbidities correlate with disease severity.

\section{Patients and methods}

This is a retrospective chart review including all patients who underwent GES at Thomas Jefferson University Hospital in Philadelphia, PA, between 2014 and 2015. This study was evaluated and approved by the Institutional Review Board at our institution (Control \#18D.081). The electronic medical record was reviewed to collect information regarding patient demographics, medical history, medications prescribed at the time of diagnosis and GES data. Data were collected and managed using REDCap electronic data capture tools hosted at Thomas Jefferson University [22].

Patients were included in the study if their GES showed $>50 \%$ retention of gastric contents $2 \mathrm{~h}$ following ingestion of a solid meal consisting of an egg and bread sandwich labeled with $0.5 \mathrm{mCi}$ of Technetium $99 \mathrm{~m}$-sulfur colloid. This is the standard for diagnosing DGE at our institution; it is based on industry standards for the Philips Medical Systems' JetStream software as well as institution-specific analyses. Patients were excluded from the presented analyses if they had a mechanical gastric outlet obstruction precluding the diagnosis of gastroparesis.

The presence of comorbid conditions serving as risk factors for the development of gastroparesis was evaluated for each patient in the study population. Major risk factors were defined as comorbid conditions that have been well established in the literature to be strongly associated with gastroparesis. Minor risk factors were defined as those postulated to be related to gastroparesis in in vivo studies or smaller case reports, but not consistently proven to be associated. Patients were assigned to categories as outlined in Fig. 1; patients with one or more major risk factors were assigned to the appropriate mutually inclusive groups 1-3, while patients with minor risk factors only or idiopathic disease were assigned to exclusive groups 4 or 5 .

\section{Statistical analysis}

To analyze the significance of demographic and scintigraphic variation, likelihood ratio tests were performed on a linear model fit to predict the percentage of gastric contents retained at $2 \mathrm{~h}$, or a generalized linear model with a logit linking function to predict the presence of a particular etiologic category. P-values were calculated using chi-square test, which assessed the significance of individual variables within linear models when controlling for other potential sources of variation. All analyses were performed using R 3.4 .

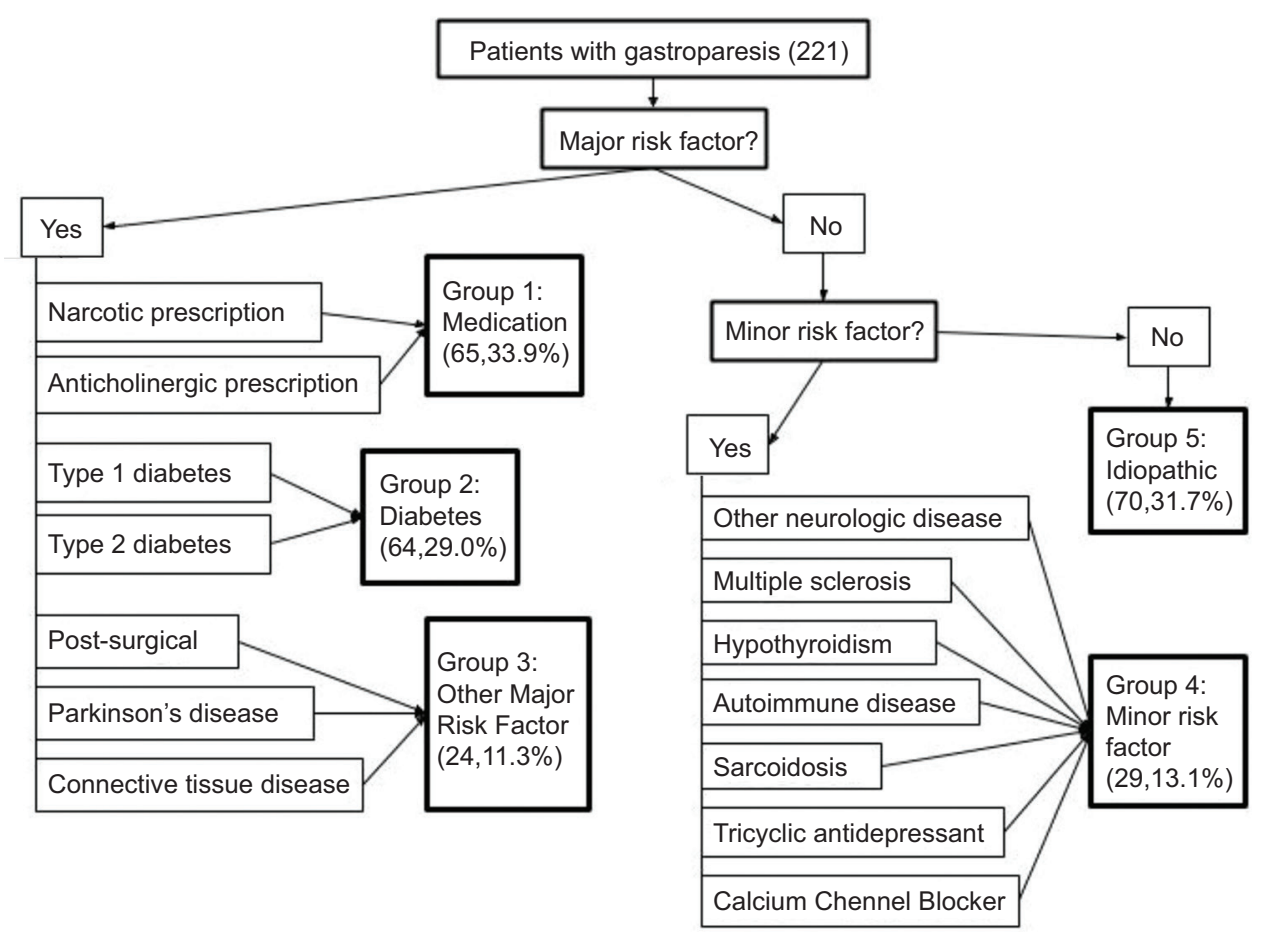

Figure 1 Grouping of patients 


\section{Results}

There were 703 patients who completed solid-phase GES at Thomas Jefferson University Hospital during 2014 and 2015. Of these patients, 262 had accelerated gastric emptying and 210 had normal gastric emptying. Ten patients were excluded because they had a physical gastric outlet obstruction, precluding a diagnosis of gastroparesis.

In total, 221 patients were included in the study. Of these patients, $77.4 \%$ were female; $56.1 \%$ were Caucasian and $31.7 \%$ were African American; 29.8\% of patients had a diagnosis of diabetes mellitus; and $33.9 \%$ of patients had an active prescription for narcotics or anticholinergic medications (Table 1). The mean body mass index (BMI) of patients included in the study was $27.6 \mathrm{~kg} / \mathrm{m}^{2}$.

Patients were grouped based on their comorbidities and risk factors for the purposes of our descriptive analysis. There were $65(29.4 \%)$ patients who met the criteria for medicationassociated gastroparesis; 64 (29.0\%) had diabetic gastroparesis, $24(11.3 \%)$ had gastroparesis associated with another major risk factor, 29 (13.1\%) had minor risk factors but no major risk factors, and $70(31.7 \%)$ were classified as true idiopathic gastroparesis. There was significant demographic variation among the etiologic categories.

In a model comparing patients with and without diabetesassociated gastroparesis, patient race $(\mathrm{P}=0.01)$, age $(\mathrm{P}=0.02)$, sex $(\mathrm{P}=0.008)$, and BMI $(\mathrm{P}<0.001)$ were independent, statistically significant predictors of having diabetes-associated gastroparesis. While only $31.7 \%$ of the study population was African American, $64.1 \%$ of patients with diabetes-associated gastroparesis in this population were African American. Men, patients with an elevated BMI, and patients diagnosed at an older age had a statistically significantly greater probability of having diabetes-associated gastroparesis than females, patients with a lower BMI, and younger patients (Tables 2,3).

In a model comparing patients with and without medication-associated gastroparesis, age $(\mathrm{P}=0.04)$ and $\mathrm{BMI}$ $(\mathrm{P}=0.02)$ were independent, statistically significant predictors of having medication-associated gastroparesis after controlling for patient sex and race. Patients with a higher BMI or diagnosed at an older age had a higher likelihood of having medication-associated gastroparesis than patients with a lower BMI and those younger at diagnosis.

Among patients with idiopathic disease, there was also a statistically significant variation in age $(\mathrm{P}<0.001)$ and $\mathrm{BMI}$ $(\mathrm{P}=0.009)$ compared to patients in the study population without idiopathic disease after controlling for sex and race. Patients with a lower BMI or those diagnosed at a younger age were more likely to have idiopathic disease than patients with a higher BMI or those older at diagnosis.

Two of the major risk factors significantly contributed to more severe delays in gastric emptying after controlling for race and sex: medications $(\mathrm{P}=0.02)$ and diabetes $(\mathrm{P}=0.03)$ (Table 4). In addition, after controlling for age, sex, BMI, and race, there was a statistically significant relationship between the number of major risk factors and the severity of a patient's DGE $(\mathrm{P}=0.004)$ (Table 5). There was no statistically significant
Table 1 Overall patient characteristics

\begin{tabular}{lc}
\hline Category & $\mathrm{N}(\%)$ \\
\hline Sex & $171(77.4)$ \\
Female & $50(22.6)$ \\
Male & \\
Race & $124(56.1)$ \\
Caucasian & $70(31.7)$ \\
African American & $23(10.4)$ \\
Other & \\
Major risk factors & $55(24.9)$ \\
Narcotic prescription & $20(9.0)$ \\
Anticholinergic prescription & $9(4.1)$ \\
Type 1 diabetes mellitus & $55(24.9)$ \\
Type 2 diabetes mellitus & $9(4.1)$ \\
Post-surgical & $2(0.9)$ \\
Parkinson's & $17(7.8)$ \\
Connective tissue disease & \\
Minor risk factors & $33(14.9)$ \\
Hypothyroidism & $15(6.8)$ \\
Multiple sclerosis & $70(31.7)$ \\
Other neurologic disease & $7(16.7)$ \\
Autoimmune disease & $3(1.4)$ \\
Sarcoidosis & $22(10.0)$ \\
Calcium channel blocker prescription & $4(1.8)$ \\
Tricyclic antidepressant prescription idiopathic & \\
\hline & \\
\hline
\end{tabular}

relationship between the number of minor risk factors and the severity of DGE $(\mathrm{P}=0.33)$.

\section{Discussion}

This study examined the most common comorbid conditions among an urban patient population diagnosed with gastroparesis. Female patients represented $77.4 \%$ of the study population, and $42.9 \%$ of patients were from minority groups. The majority of patients carried at least one risk factor for gastroparesis, while $32 \%$ of patients had true idiopathic disease. A higher burden of major risk factors was significantly associated with a more severe delay in gastric emptying.

To our knowledge, this is the first study to examine the comorbidities, or risk factors for DGE among an urban population of gastroparesis patients, and the first to attempt to establish the impact of multiple comorbid conditions on the objective severity of DGE. Our patient demographics are similar to those in previous publications with regard to the average age of patients at the time of diagnosis and the 
Table 2 Race and risk factors

\begin{tabular}{|c|c|c|c|c|c|}
\hline \multirow[t]{2}{*}{ Patient Group } & \multirow[t]{2}{*}{ Total } & \multicolumn{3}{|c|}{ Race (\%) } & \multirow[t]{2}{*}{ P-value } \\
\hline & & Caucasian & African American & Other & \\
\hline Overall & 221 & 56.1 & 31.7 & 12.2 & NA \\
\hline Medication-associated & 65 & 56.9 & 32.3 & 10.8 & NS \\
\hline Diabetes mellitus & 64 & 34.4 & 64.1 & 1.5 & 0.01 \\
\hline Other major risk factor & 24 & 75.0 & 20.8 & 4.2 & 0.04 \\
\hline Minor risk factor only & 29 & 62.1 & 27.6 & 10.3 & NS \\
\hline True idiopathic & 70 & 58.6 & 24.3 & 17.1 & NS \\
\hline
\end{tabular}

${ }^{\star}$ P-values represent a controlled comparison between patients within a specific gastroparesis group and patients not in that group

NA, not applicable; NS, nonsignificant

Table 3 Demographics and risk factors

\begin{tabular}{|c|c|c|c|c|c|}
\hline Patient Group & Total & Average age (years) & P-value & Average BMI & P-value \\
\hline Overall & 221 & 47.9 & NA & 27.6 & NA \\
\hline Medication-associated & 65 & 51.1 & 0.02 & 29.4 & 0.04 \\
\hline Diabetes mellitus & 64 & 53.9 & 0.02 & 31.5 & $<0.001$ \\
\hline Other major risk factor & 24 & 52.3 & NS & 27.2 & NS \\
\hline Minor risk factor only & 29 & 51.4 & NS & 25.5 & NS \\
\hline True idiopathic & 70 & 39.6 & $<0.001$ & 25.0 & 0.009 \\
\hline
\end{tabular}

${ }^{\star} \mathrm{P}$-values represent a controlled comparison between patients within a specific gastroparesis group and patients not in that group

NA, not applicable; NS, nonsignificant; BMI, body mass index

Table 4 Risk factors and severity of delayed gastric emptying

\begin{tabular}{lc} 
Risk factors & Mean percent retained at $2 \mathrm{~h}(\%)$ \\
\hline Medication-associated & $74.5(\mathrm{n}=65, \mathrm{SD}=14.2), \mathrm{P}=0.02$ \\
Diabetes mellitus & $73.5(\mathrm{n}=64, \mathrm{SD}=14.8), \mathrm{P}=0.03$ \\
Other major risk factor & $73.0(\mathrm{n}=24, \mathrm{SD}=14.5)$ \\
Minor risk factor only & $68.7(\mathrm{n}=29, \mathrm{SD}=13.4)$ \\
True idiopathic & $67.1(\mathrm{n}=70, \mathrm{SD}=11)$ \\
Overall & $70.3(\mathrm{n}=221, \mathrm{SD}=13.3)$
\end{tabular}

$S D$, standard deviation

Table 5 Number of risk factors and severity of delayed gastric emptying $(\mathrm{P}=0.004)$

\begin{tabular}{lc}
\hline $\begin{array}{l}\text { Number of major } \\
\text { risk factors }\end{array}$ & $\begin{array}{c}\text { Mean percentage retained } \\
\text { at } 2 \mathrm{~h}(\%)\end{array}$ \\
\hline 0 & $67.6(\mathrm{n}=99, \mathrm{SD}=11.7)$ \\
1 & $70.9(\mathrm{n}=82, \mathrm{SD}=13.3)$ \\
2 & $76.3(\mathrm{n}=36, \mathrm{SD}=15.1)$ \\
3 & $90.6(\mathrm{n}=3, \mathrm{SD}=22.6)$ \\
4 & $85(\mathrm{n}=1)$ \\
\hline$S D$, standard deviation &
\end{tabular}

predominance of female patients [12,23-25]. Importantly, our study is among the first to include a significant representation of minority populations in its analysis.
Previous studies have attempted to correlate patient symptoms with the degree of DGE, but few have examined the relationship between etiology of gastroparesis and the severity of DGE [25-28]. We have shown that patients with diabetic or medication-associated gastroparesis and those with multiple major risk factors in combination had significantly more severe DGE compared to those with idiopathic gastroparesis.

A wide range of medications have been implicated in delaying gastric emptying. Based on the available evidence, we considered narcotic analgesics and anticholinergic medications to be significantly related to DGE [29-31]. In our study, 25\% of patients had an active prescription for narcotics at the time of diagnosis - higher than the national opioid prescribing rate [32].

Calcium channel blockers and tricyclic antidepressants are thought to impact gastric motility, but data are lacking on a clear relationship with DGE [33-36]. For this reason, we considered both of these medications to be minor risk factors for the disease.

A majority of our patients had a prescription for at least one medication that has been implicated in delaying gastric emptying, a finding that has not previously been well described. According to the 2008 Consensus Recommendations for Gastric Emptying Scintigraphy, most centers recommend that patients stop gastric motility-delaying agents $48-72 \mathrm{~h}$ prior to undergoing GES [3]. Perhaps it could be beneficial to perform GES while patients are still taking all medications; this would provide the most accurate representation of the patient's DGE as it occurs on a daily basis. 
Gastroparesis is a well-known complication of diabetes [7,37]. In this study, African American patients were more likely to have diabetic-associated gastroparesis than gastroparesis patients of any other race. This supports the findings of prior studies with a smaller proportion of minority patients $[38,39]$. While rates of diabetes mellitus in the community are also greater among African Americans (12.1 vs. $7.6 \%$ for Caucasians) [40], our findings indicate a disproportionate impact on minority populations.

Medical conditions that have been clearly linked with gastroparesis include post-surgical nerve injury, Parkinson's disease, autoimmune diseases and connective tissue diseases, such as systemic sclerosis and Sjögren's syndrome [14,16-18,20,41-48]. Interestingly, our population included a significant percentage of patients with hypothyroidism (16.7\%), significantly higher than the national prevalence of $4.6 \%$ [48]. While the hypothyroidism state is associated with delayed esophageal and gastric motility, we did not consider a diagnosis of hypothyroidism to be a major risk factor for gastroparesis, as evidence suggests that once patients are stabilized on appropriate medication, the impact on motility is typically resolved [49-52].

Idiopathic gastroparesis is diagnosed when no other cause is identified, though it is often unclear in previous studies which potential causes were considered before patients were labeled with the diagnosis $[13,52,53]$. As is standard in the literature [54-56], we included patients with a post-viral syndrome as patients with idiopathic disease, assuming that they did not have a major risk factor.

In our study, we relied on the available literature to describe exposures and comorbid conditions as risk factors for gastroparesis. Our individual patient data were limited to the availability of details in the medical record. We were unable to gather information regarding indicators of the severity and control of patients' underlying chronic diseases, or the doses of their prescribed medications, both of which can impact gastric emptying. In addition, the gold standard for evaluation of DGE is 4-h nuclear emptying scintigraphy. However, at our institution patients classically undergo a 2-h scan unless there is doubt regarding the results. Finally, it is difficult to determine which medications were held prior to scintigraphic testing and for how long. These patient instructions are physiciandependent and there is no clear documentation in our record system regarding the instructions provided to the patient or followed by the patient.

In conclusion, the results of this retrospective study indicate that patients diagnosed with gastroparesis often have multiple comorbid conditions, and the number of risk factors that they carry significantly impacts the severity of their disease. If we continue to limit patients into broad categories of diabetic and idiopathic gastroparesis, we may be missing opportunities to better address the true underlying etiology of the disease and to treat patients optimally. In addition, we have demonstrated a racial disparity in the etiology of gastroparesis, with African American patients being more likely to have diabetic disease than patients of other races.

Further research should be done to better elucidate the impact of certain medications, comorbid conditions and socioeconomic status on gastric emptying. Additionally, physicians should consider patients' individual risk factors when ordering, protocoling, and interpreting GES studies in order to best evaluate the extent of the disease and to provide optimal medical management.

\section{Summary Box}

\section{What is already known:}

- Little is known about the causes of gastroparesis beyond severe diabetes

- Many patients are characterized as having idiopathic gastroparesis

\section{What the new findings are:}

- A large proportion of gastroparesis patients receive narcotic prescriptions

- African American patients seem to be at higher risk for diabetic gastroparesis than patients of other races

- Patients with more conditions known to be associated with gastroparesis had more severe objective delays in gastric emptying

\section{References}

1. Camilleri M, Parkman HP, Shafi MA, Abell TL, Gerson L; American College of Gastroenterology. Clinical guideline: management of gastroparesis. Am J Gastroenterol 2013;108:18-37.

2. Parkman HP, Hasler WL, Fisher RS; American Gastroenterological Association. American Gastroenterological Association technical review on the diagnosis and treatment of gastroparesis. Gastroenterology 2004;127:1592-1622.

3. Abell TL, Camilleri $\mathrm{M}$, Donohoe $\mathrm{K}$, et al; American Neurogastroenterology and Motility Society and the Society of Nuclear Medicine. Consensus recommendations for gastric emptying scintigraphy: a joint report of the American Neurogastroenterology and Motility Society and the Society of Nuclear Medicine. Am J Gastroenterol 2008;103:753-763.

4. Jung HK, Choung RS, Locke GR 3rd, et al. The incidence, prevalence, and outcomes of patients with gastroparesis in Olmsted County, Minnesota, from 1996 to 2006. Gastroenterology 2009; 136:1225-1233.

5. Choung RS, Locke GR 3rd, Schleck CD, Zinsmeister AR, Melton LJ 3rd, Talley NJ. Risk of gastroparesis in subjects with type 1 and 2 diabetes in the general population. Am J Gastroenterol 2012;107:82-88.

6. Camilleri M. Clinical practice. Diabetic gastroparesis. N Engl J Med 2007;356:820-829.

7. Camilleri M, Bharucha AE, Farrugia G. Epidemiology, mechanisms, and management of diabetic gastroparesis. Clin Gastroenterol Hepatol 2011;9:5-12.

8. Grover M, Farrugia G, Lurken MS, et al; NIDDK Gastroparesis Clinical Research Consortium. Cellular changes in diabetic and idiopathic gastroparesis. Gastroenterology 2011;140:1575-1585.e8. 
9. Janatuinen E, Pikkarainen P, Laakso M, Pyörälä K. Gastrointestinal symptoms in middle-aged diabetic patients. Scand J Gastroenterol 1993;28:427-432.

10. Jones KL, Russo A, Stevens JE, Wishart JM, Berry MK, Horowitz M. Predictors of delayed gastric emptying in diabetes. Diabetes Care 2001;24:1264-1269.

11. Kong MF, Horowitz M, Jones KL, Wishart JM, Harding PE. Natural history of diabetic gastroparesis. Diabetes Care 1999;22:503-507.

12. Soykan I, Sivri B, Sarosiek I, Kiernan B, McCallum RW. Demography, clinical characteristics, psychological and abuse profiles, treatment, and long-term follow-up of patients with gastroparesis. Dig Dis Sci 1998;43:2398-2404.

13. Parkman HP. Idiopathic gastroparesis. Gastroenterol Clin North Am 2015;44:59-68.

14. Kumar S, Singh J, Rattan S, DiMarino AJ, Cohen S, Jimenez SA. Pathogenesis and clinical manifestations of gastrointestinal involvement in systemic sclerosis. Aliment Pharmacol Ther 2017;45:883-898.

15. Pande H, Lacy BE, Crowell MD. Inflammatory causes of gastroparesis: report of five cases. Dig Dis Sci 2002;47:2664-2668.

16. Fich A, Neri M, Camilleri M, Kelly KA, Phillips SF. Stasis syndromes following gastric surgery: clinical and motility features of 60 symptomatic patients. J Clin Gastroenterol 1990;12:505-512.

17. Samin K, Alam I, Riaz S, Alam S, Baxter JN. Gastro-ileal stenosis and gastroparesis after a biliopancreatic diversion. Obes Surg 2006;16:1243-1245.

18. Pfeiffer RF. Gastrointestinal dysfunction in Parkinson's disease. Parkinsonism Relat Disord 2011;17:10-15.

19. Dhamija R, Tan KM, Pittock SJ, Foxx-Orenstein A, Benarroch E, Lennon VA. Serologic profiles aiding the diagnosis of autoimmune gastrointestinal dysmotility. Clin Gastroenterol Hepatol 2008;6:988-992.

20. Bar-Natan M, Larson GM, Stephens G, Massey T. Delayed gastric emptying after gastric surgery. Am J Surg 1996;172:24-28.

21. Camilleri M, Grover M, Farrugia G. What are the important subsets of gastroparesis? Neurogastroenterol Motil 2012;24:597-603.

22. Harris PA, Taylor R, Thielke R, Payne J, Gonzalez N, Conde JG. Research electronic data capture (REDCap) - a metadata-driven methodology and workflow process for providing translational research informatics support. J Biomed Inform 2009;42:377-381.

23. Parkman HP, Yates K, Hasler WL, et al; National Institute of Diabetes and Digestive and Kidney Diseases Gastroparesis Clinical Research Consortium. Clinical features of idiopathic gastroparesis vary with sex, body mass, symptom onset, delay in gastric emptying, and gastroparesis severity. Gastroenterology 2011;140:101-115.

24. Dudekula A, Rahim S, Bielefeldt K. Time trends in gastroparesis treatment. Dig Dis Sci 2014;59:2656-2665.

25. Parkman HP, Yates K, Hasler WL, et al; National Institute of Diabetes and Digestive and Kidney Diseases Gastroparesis Clinical Research Consortium. Similarities and differences between diabetic and idiopathic gastroparesis. Clin Gastroenterol Hepatol 2011;9:1056-1064.

26. Horowitz M, Harding PE, Maddox AF, et al. Gastric and oesophageal emptying in patients with type 2 (non-insulin-dependent) diabetes mellitus. Diabetologia 1989;32:151-159.

27. Koch KL, Stern RM, Stewart WR, Vasey MW. Gastric emptying and gastric myoelectrical activity in patients with diabetic gastroparesis: effect of long-term domperidone treatment. Am J Gastroenterol 1989;84:1069-1075.

28. Talley NJ, Shuter B, McCrudden G, Jones M, Hoschl R, Piper DW. Lack of association between gastric emptying of solids and symptoms in nonulcer dyspepsia. J Clin Gastroenterol 1989;11:625-630.

29. Patrick A, Epstein O. Review article: gastroparesis. Aliment Pharmacol Ther 2008;27:724-740.
30. Nimmo WS, Heading RC, Wilson J, Tothill P, Prescott LF. Inhibition of gastric emptying and drug absorption by narcotic analgesics. Br J Clin Pharmacol 1975;2:509-513.

31. Yuan CS, Foss JF, O’Connor M, Roizen MF, Moss J. Effects of lowdose morphine on gastric emptying in healthy volunteers. J Clin Pharmacol 1998;38:1017-1020.

32. Centers for Disease Control and Prevention. Annual surveillance report of drug-related risks and outcomes - United States, 2017. Available from: https://www.cdc.gov/drugoverdose/pdf/ pubs/2017-cdc-drug-surveillance-report.pdf [Accessed 13 February 2020].

33. Brage R, Cortijo J, Esplugues J, Esplugues JV, Martí-Bonmatí E, Rodriguez C. Effects of calcium channel blockers on gastric emptying and acid secretion of the rat in vivo. Br J Pharmacol 1986;89:627-633.

34. Parkman HP, Van Natta ML, Abell TL, et al. Effect of nortriptyline on symptoms of idiopathic gastroparesis: the NORIG randomized clinical trial. JAMA 2013;310:2640-2649.

35. Talley NJ, Locke GR, Saito YA, et al. Effect of amitriptyline and escitalopram on functional dyspepsia: a multicenter, randomized controlled study. Gastroenterology 2015;149:340-349.e2.

36. Prakash C, Lustman PJ, Freedland KE, Clouse RE. Tricyclic antidepressants for functional nausea and vomiting: clinical outcome in 37 patients. Dig Dis Sci 1998;43:1951-1956.

37. Keshavarzian A, Iber F, Vaeth J. Gastric emptying in patients with insulin-requiring diabetes mellitus. Am J Gastroenterol 1987;82:29-35.

38. Friedenberg FK, Kowalczyk M, Parkman HP. The influence of race on symptom severity and quality of life in gastroparesis. J Clin Gastroenterol 2013;47:757-761.

39. Parkman HP, Yamada G, Van Natta ML, et al. Ethnic, racial, and sex differences in etiology, symptoms, treatment, and symptom outcomes of patients with gastroparesis. Clin Gastroenterol Hepatol 2019;17:1489-1499.

40. Gaskin DJ, Thorpe RJ Jr, McGinty EE, et al. Disparities in diabetes: the nexus of race, poverty, and place. Am J Public Health 2014;104:2147-2155.

41. Sheiner HJ, Quinlan MF, Thompson IJ. Gastric motility and emptying in normal and post-vagotomy subjects. Gut 1980;21:753-759.

42. Marie I, Levesque H, Ducrotté P, et al. Gastric involvement in systemic sclerosis: a prospective study. Am J Gastroenterol 2001;96:77-83.

43. Greydanus MP, Camilleri M. Abnormal postcibal antral and small bowel motility due to neuropathy or myopathy in systemic sclerosis. Gastroenterology 1989;96:110-115.

44. Nelson A, Mouchli M, Valentin N, et al. Ehlers Danlos syndrome and gastrointestinal manifestations: A 20-year experience at Mayo Clinic. Neurogastroenterol Motil 2015;27:1657-1666.

45. Hammar O, Ohlsson B, Wollmer P, Mandl T. Impaired gastric emptying in primary Sjogren's syndrome. J Rheumatol 2010;37:2313-2318.

46. Golden SH, Robinson KA, Saldanha I, Anton B, Ladenson PW. Prevalence and incidence of endocrine and metabolic disorders in the United States: a comprehensive review. J Clin Endocrinol Metab 2009;94:1853-1878.

47. Kahraman H, Kaya N, Demircali A, Bernay I, Tanyeri F. Gastric emptying time in patients with primary hypothyroidism. Eur J Gastroenterol Hepatol 1997;9:901-904.

48. Yaylali O, Kirac S, Yilmaz M, et al. Does hypothyroidism affect gastrointestinal motility? Gastroenterol Res Pract 2009;2009:529802.

49. Ebert EC. The thyroid and the gut. J Clin Gastroenterol 2010;44:402-406.

50. Vittal H, Farrugia G, Gomez G, Pasricha PJ. Mechanisms of disease: the pathological basis of gastroparesis-a review of 
experimental and clinical studies. Nat Clin Pract Gastroenterol Hepatol 2007;4:336-346.

51. El-Maghraby TA, Shalby NM, Al-Tawdy MH, Salem S. Gastric motility dysfunction in patients with multiple sclerosis assessed by gastric emptying scintigraphy. Can J Gastroenterol 2005; 19:141-145.

52. Haensch CA, Jörg J. Autonomic dysfunction in multiple sclerosis. J Neurol 2006;253 Suppl 1:I3-I9.

53. Zárate N, Mearin F, Wang XY, Hewlett B, Huizinga JD, Malagelada JR. Severe idiopathic gastroparesis due to neuronal and interstitial cells of Cajal degeneration: pathological findings and management. Gut 2003;52:966-970.

54. Sigurdsson L, Flores A, Putnam PE, Hyman PE, Di Lorenzo C. Postviral gastroparesis: presentation, treatment, and outcome. $J$ Pediatr 1997;131:751-754.

55. Bityutskiy LP, Soykan I, McCallum RW. Viral gastroparesis: a subgroup of idiopathic gastroparesis-clinical characteristics and long-term outcomes. Am J Gastroenterol 1997;92:1501-1504.

56. Naftali T, Yishai R, Zangen T, Levine A. Post-infectious gastroparesis: clinical and electrogastrographic aspects. $J$ Gastroenterol Hepatol 2007;22:1423-1428. 